\title{
SWELLING PRESSURE OF POLY(VINYLMETHYLETHER) GEL (PVMEG) IN SWELLING PROCESS
}

\author{
XIA HUANG, HaJime UNNO, TAKASHI AKEHATA \\ AND OKIHIKO HIRASA \\ Department of Environmental Chemistry and Engineering, \\ Tokyo Institute of Technology, Yokohama 227
}

Key Words: Polymer Gel, Swelling Pressure, Temperature, Porosity, Hydrogen Bond, Anion Group

\begin{abstract}
The swelling pressure appearing in the swelling process of nonionic poly(vinylmethylether) gel (PVMEG) was studied experimentally. When a piece of PVMEG was placed in the space between two plates, it exerted a swelling pressure on the plates. Larger swelling pressure was observed under the conditions of lower temperature or smaller space between the plates, i.e., smaller gel porosity. The swelling pressure was primarily due to the contribution of the hydrogen bond of methoxyl groups in the polymer network with water molecules. The effect of salt on the swelling pressure of gel correlated well with the ratio of the valency to radius of the anion group in the salt.
\end{abstract}

\section{Introduction}

Recently, various engineering applications of polymer gels, such as separation of organic substances in water by utilizing the hydrophobic property of a gel's constituent segments, ${ }^{2)}$ concentration of oxygen by permeating air through hydrogel supported by an inorganic porous membrane ${ }^{7)}$ and the like have been studied intensively. These trends are partly due to the advancement of theoretical research into the physical properties of gels. In our study, an application of nonionic poly(vinylmethylether) gel (PVMEG), which swells and shrinks respectively below and above the temperature of $310 \mathrm{~K},{ }^{3.5)}$ to the dewatering of waste sludges was proposed and tested. ${ }^{4.61}$

The engineering application of sludge dewatering is closely related to the water-absorbing process, i.e., the swelling process, of gel. The process is controlled by the swelling pressure. For this application, therefore, it is necessary to clarify the characteristics of the swelling pressure of gel.

In the present study, characteristics of the swelling pressure of PVMEG, including the effect of salts contained in waste sludges usually encountered in dewatering treatment were examined experimentally, and the mechanism of gel swelling was investigated.

\section{Experimental}

The experimental apparatus for measuring the swelling pressure of PVMEG is shown in Fig. 1. A test container [B] containing distilled water or salt so-

Received March I, 1988. Correspondence concerning this article should be addressed to H. Unno, Dept. of Bioengineering, Tokyo Institute of Technology. O. Hirasa is at Research Institute for Polymers and Textiles. lution was placed in a water bath $[\mathrm{A}]$ of constant temperature. A shrunken cylindrical gel $[\mathrm{C}]$ of initial diameter $1.0 \times 10^{-2} \mathrm{~m}$ and initial length $1.35 \times 10^{-2} \mathrm{~m}$ at a temperature of $321 \mathrm{~K}$ was placed on an acrylic plate [D], being set a space $\Delta H$ from an upper fixed plate. The temperature $321 \mathrm{~K}$, higher than the transition temperature $310 \mathrm{~K}$, was tried as an example of temperatures for a shrunken gel. The force exerted by a swollen gel on the plate [D] was transmitted to a stress meter $[G]$ through a nylon string $[E]$ and a wheel $[\mathrm{F}]$, and was recorded on a strip chart.

The salts tested to examine their effect on the swelling pressure of gel were $\mathrm{NaI}, \mathrm{KNO}_{3}, \mathrm{Ca}\left(\mathrm{NO}_{3}\right)_{2}$, $\mathrm{NaCl}, \mathrm{KCl}, \mathrm{Na}_{2} \mathrm{HPO}_{4}$ and $\mathrm{Na}_{2} \mathrm{SO}_{4}$.

\section{Results and Discussion}

\subsection{Swelling pressure of PVMEG in distilled water}

Figure 2 shows examples of the time course of

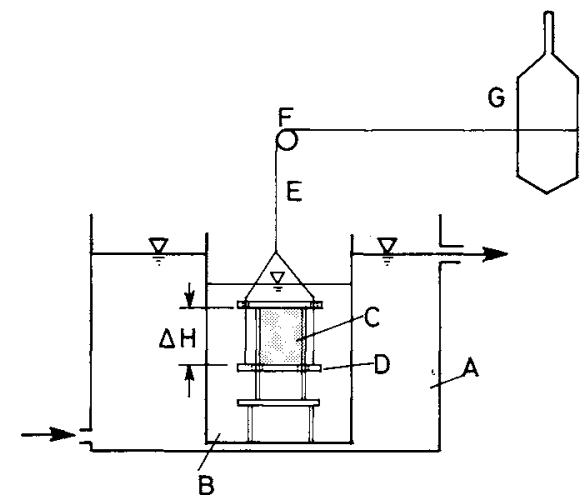

Fig. 1. Experimental setup for measuring the swelling pressure of PVMEG

A, water bath; $B$, container; $C$, cylindrical gel; D, setting plate; $\mathrm{E}$, nylon string; $F$, wheel; $\mathrm{G}$, stress meter 


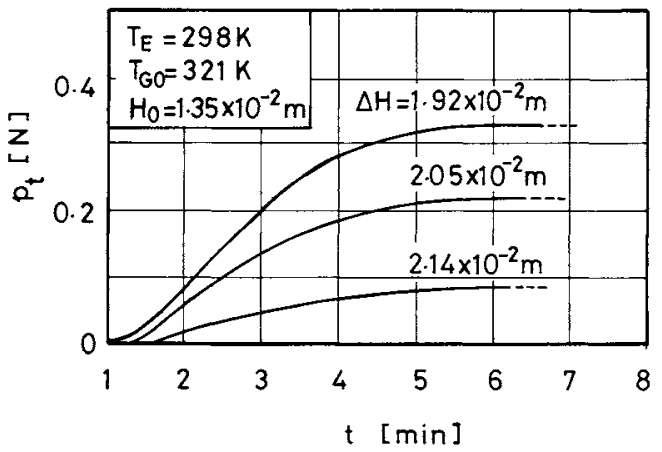

Fig. 2. Transient swelling force exerted by a gel on the plate [D] (---, apparent equilibrium swelling force)

swelling force exerted by the gel on the plate $[D]$ in distilled water at temperature of $298 \mathrm{~K}$. A shrunken gel of temperature $321 \mathrm{~K}$ placed on the plate swelled gradually with decrease of the gel's temperature by heat transfer. When the gel swelled to the size $\Delta H$, an apparent swelling force $p_{t}$ on the plate [D] appeared, increasing to an apparent equilibrium value $p$. The value $p$, being "apparent equilibrium swelling force," can be regarded as a force on the cross section including pore space of a gel which is compressed from its equilibrium size under free condition at $298 \mathrm{~K}$ to the size $\Delta H$. The larger the space $\Delta H$, i.e., the smaller the stress by compression of gel, the smaller is the apparent equilibrium swelling force.

Figure 3 shows the changes of equilibrium swelling pressure $P$ for different temperatures, the pressure being defined as the value per cross area of polymer network in gel and called a "swelling pressure" for brevity. The porosity $\phi$ of gel was evaluated by Eq. (1) by assuming that the structure of the gel was isotropic and that there was no void in the initial shrunken gel filled with a small amount of water.

$$
\begin{aligned}
\phi & =\left(V-V_{0}\right) / V \\
& =1-\left(H_{0} / \Delta H\right)^{3}
\end{aligned}
$$

where $\Delta H$ is the distance between the two plates, i.e., the length of swollen gel, and $H_{0}$ and $V_{0}$ respectively express the initial length and volume of shrunken gel. The lower the temperature, the larger the swelling pressure became. By decreasing $\Delta H$, i.e., decreasing the porosity of gel, the swelling pressure increased.

A phenomenological explanation of gel swelling has been studied, the Eq. (2) was presented to express the osmotic or swelling pressure of an ionic gel. ${ }^{1,8)}$ In the equation a characteristic parameter $f$, which represents a number of dissociated counter ions per effective polymer chain, was introduced to describe the contribution of dissociated ions from the network to the swelling pressure.

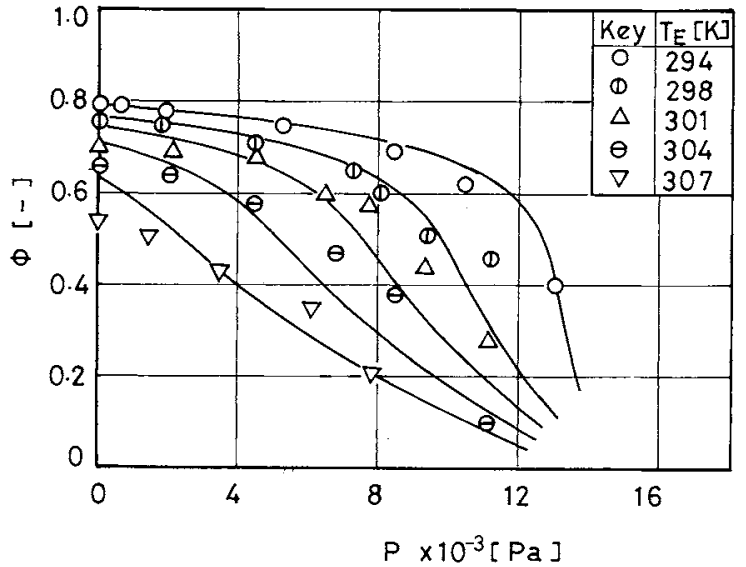

Fig. 3. Relation between porosity $\phi$ and swelling pressure $P$ at different temperatures

$$
\begin{aligned}
P= & -\frac{N k T}{v}\left\{\ln (1-\psi)+\psi+\frac{\Delta F}{2 k T} \psi^{2}\right\} \\
& +k T v\left\{\frac{\psi}{2 \psi_{0}}-\left(\frac{\psi}{\psi_{0}}\right)^{1 / 3}\right\}+v f k T\left(\frac{\psi}{\psi_{0}}\right)
\end{aligned}
$$

where $\psi_{0}$ and $\psi$ represent the volume fractions of uncross-linked single polymer chain and of crosslinked network in gel, respectively; $v$ is the molar volume of solvent; $v$ is the number of constituent chains per unit volume at $\psi=\psi_{0}$; and $\Delta F$ is the change of free energy associated with the contact between polymer segments in a shrunken state and solvent molecules.

On the right-hand side of Eq. (2), the first term represents the swelling pressure from change of the mixing free energy, the second is that from the rubber elasticity, and the third is that from the ionization of the gel's network.

Equation (2) is to be modified for application to the present gel because of the difference in the nature of gels studied, PVMEG being a nonionic gel. As described in the previous study, ${ }^{3}$ the swelling and shrinking phenomena of PVMEG are thought to be due to the reversible hydration and dehydration reactions between the methoxyl group of the polymer network and water molecules as shown in Eq. (3).

$$
\begin{aligned}
& \text { (Hydrated PVMEG) (Dehydrated PVMEG) } \\
& \begin{array}{cc}
\left(\mathrm{CH}_{2}-\mathrm{CH}\right)_{n}-\underset{\text { cool }}{\stackrel{\text { heat }}{\rightleftarrows}}-\left(\mathrm{CH}_{2}-\mathrm{CH}\right)_{n}-+\mathrm{H}_{2} \mathrm{O} \\
\mathrm{OCH}_{3} & \mathrm{OCH}_{3}
\end{array} \\
& \text { } \mathrm{HOH}
\end{aligned}
$$

The hydrogen bond of the polymer network with water molecules will make a contribution to the swelling pressure of the gel, similar to that from the ionization of an ionic gel. The contribution will be a function of the temperature and the swollen volume of gel. Since at present no reliable theory has been 
presented for the contribution, a trial Eq. (4) for expressing the contribution was examined experimentally.

$$
\begin{aligned}
P_{H} & =f_{H}(1-T / 310)^{q}\left\{1-\gamma\left(V-V_{0}\right) / V_{0}\right\} \\
& =f_{H}(1-T / 310)^{q}\left\{1-\gamma\left(\psi_{0} / \psi-1\right)\right\}
\end{aligned}
$$

where $P_{H}$ is swelling pressure due to the contribution of hydrogen bond, and $f_{H}, q$ and $\gamma$ are experimental coefficients. The equation should be tested in the range of temperature less than the transition temperature of $310 \mathrm{~K}$. The coefficient $\gamma$ expresses the fraction of decreased number of hydrogen bonds by increasing the gel's volume by the same value of $V_{0}$. Using Eq. (4), the corresponding equation of Eq. (2) was then tried to express the swelling pressure for the present gel as shown by Eq. (5).

$$
\begin{aligned}
P= & -\frac{N k T}{v}\left\{\ln (1-\psi)+\psi+\frac{\Delta F}{2 k T} \psi^{2}\right\} \\
& +k T v\left\{\frac{\psi}{2 \psi_{0}}-\left(\psi / \psi_{0}\right)^{1 / 3}\right\} \\
& +f_{H}(1-T / 310)^{q}\left\{1-\gamma\left(\psi_{0} / \psi-1\right)\right\}
\end{aligned}
$$

The parameters $q, \gamma, \psi_{0}, \Delta F, v$ and $f_{H}$ in Eq. (5) were determined by fitting the calculated results with the experimental data. The fitting was carried out as follows: first, the values of $q, \gamma$ and $\psi_{0}$, which have a remarkable effect on the functional form of Eq. (5), were estimated considering the experimental $\phi-P$ relations, $\phi$ being equal to $\left(1-\psi / \psi_{0}\right)$. Next, the values of $\Delta F, v$ and $f_{H}$ were calculated by solving three simultaneous equations obtained by three sets of experimental data with predetermined values of $q, \gamma$ and $\psi_{0}$. The calculated results fitting the experimental data best are shown in Fig. 3 by solid lines. The values of the fitting parameters were as follows:

$$
\begin{array}{ll}
q=0.004[-] & \gamma=0.06[-] \\
\psi_{0}=0.06[-] & \Delta F=5.06 \times 10^{-21}[\mathrm{~J}] \\
v=1.14 \times 10^{26}\left[\mathrm{~m}^{-3}\right] & f_{H}=3.0 \times 10^{5}[\mathrm{~Pa}]
\end{array}
$$

By using Eq. (5) and the values of the parameters shown in Eq. (6), the contribution of each term of Eq. (5) is evaluated in Fig. 4, where $P_{M}, P_{E}$ and $P_{H}$ are respectively the swelling pressure due to the change of the mixing free energy (the first term of Eq. (5)), that due to rubber elasticity (the second term of Eq. (5)) and that due to the contribution of hydrogen bond of the polymer network (the third term of Eq. (5)). The contribution of hydrogen bond $\mathrm{P}_{H}$, to the swelling pressure was largest, decreasing gradually as the porosity $\phi$ increased. The contribution $P_{H}$ was compensated by the increase of the negative contributions of $P_{M}$ and $P_{E}$. Finally, an equilibrium state of swelling is reached by balancing these three pressure com-

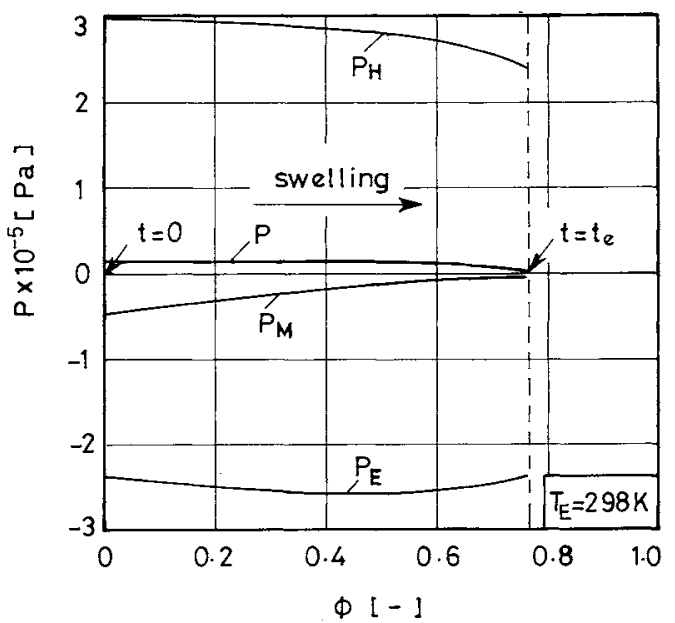

Fig. 4. Evaluated swelling pressure $P_{M}$ due to mixing free energy change, $P_{E}$ due to rubber elasticity and $P_{H}$ due to contribution of hydrogen bond of polymer network

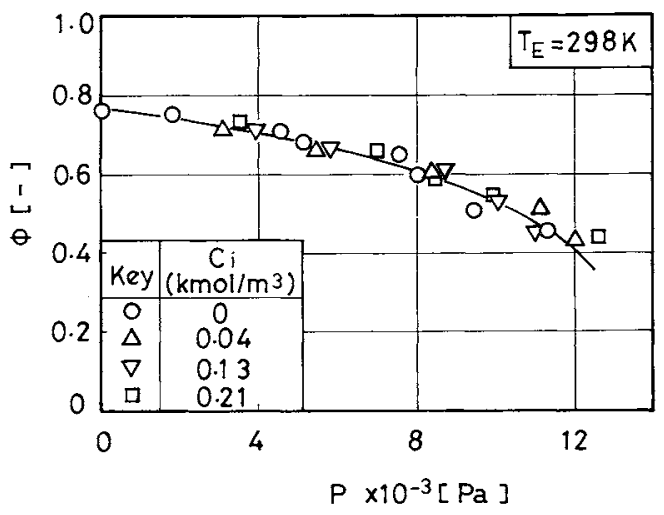

Fig. 5. Relation between porosity $\phi$ and swelling pressure $P$ in $\mathrm{Ca}\left(\mathrm{NO}_{3}\right)_{2}$ solution

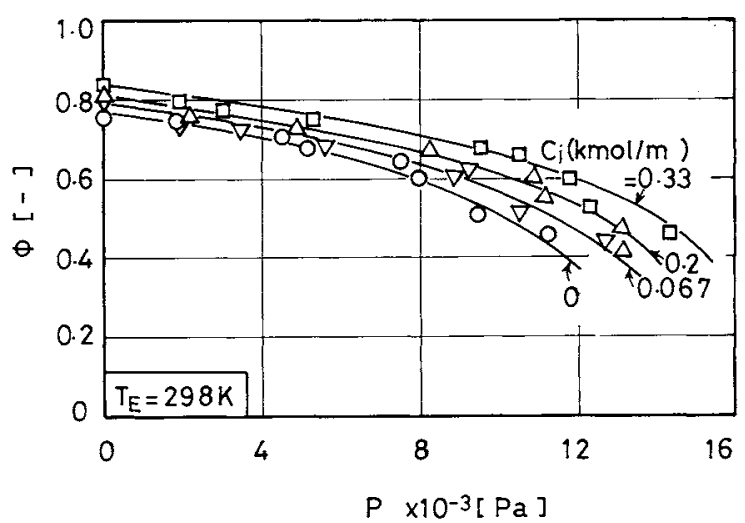

Fig. 6. Relation between porosity $\phi$ and swelling pressure $P$ in $\mathrm{NaI}$ solution

ponents.

\subsection{Swelling pressure of PVMEG in salt solution}

The effect of salt on PVMEG's swelling pressure was found to go with the phenomena observed in the swelling process of the ge ${ }^{5)}$ and to be characterized by the salt used. Typical examples of the results are shown in Figs. 5, 6 and 7. 




Fig. 7. Relation between porosity $\phi$ and swelling pressure $P$ in $\mathrm{NaCl}$ solution

Figure 5 shows the relation between the porosity and the swelling pressure in $\mathrm{Ca}\left(\mathrm{NO}_{3}\right)_{2}$ solution. The curve is not remarkably affected by the concentration of $\mathrm{Ca}\left(\mathrm{NO}_{3}\right)_{2}$. A similar effect was observed in $\mathrm{KNO}_{3}$ solution.

Increases in the swelling pressure of gel in $\mathrm{NaI}$ solution were observed as shown in Fig. 6. Contrary to the case of $\mathrm{NaI}$, the swelling pressure in the solution of $\mathrm{NaCl}$ decreased with increasing concentration of $\mathrm{NaCl}$ as shown in Fig. 7. Similar results for the solutions of $\mathrm{Na}_{2} \mathrm{HPO}_{4}, \mathrm{Na}_{2} \mathrm{SO}_{4}$ and $\mathrm{KCl}$ were observed.

Figure 8 shows the effect of all the salts examined on the difference of the swelling pressure $\Delta P$ between the values observed in distilled water and salt solution at a gel porosity of 0.4 and a temperature of $298 \mathrm{~K}$. As shown in the figure, the change of swelling pressure is related to the kind and concentration of the anion group of the salt independently of the relevant cation. The result was similar to that obtained in the study on the swelling process of the gel in salt solutions, which was concerned with the interaction of polymer network with water molecules and anions. ${ }^{5}$ The swelling pressure of gel decreased, i.e., the positive value of $\Delta P$ increased, in solutions of salts consisting of polyvalent anion, e.g., $\mathrm{SO}_{4}^{2-}$ and $\mathrm{HPO}_{4}^{2-}$ or a larger-size anion, e.g., $\mathrm{Cl}^{-}$.

The slope of $\Delta P$ vs. $C_{i}$ at infinite dilution in Fig. 8, i.e. $\beta_{P}=\lim _{C_{i} \rightarrow 0}\left(\Delta P / C_{i}\right)$, is plotted against the ratio $n_{i} / r_{i}$, $n_{i}$ and $r_{i}$ being respectively the valency and radius of the anion. The plot is similar to that described in the previous paper. ${ }^{5)}$ A linear relation was obtained as shown in Fig. 9, and is written as

$$
\beta_{P}=5.2 \times 10^{-5}\left(n_{i} / r_{i}-4.8 \times 10^{9}\right)
$$

The coefficient $5.2 \times 10^{-5}$ will take different values as temperature changes because the change of gel volume in salt solutions depends on temperature as reported elsewhere. ${ }^{5)}$ The relation indicated that the swelling pressure in salt solution is primarily con-

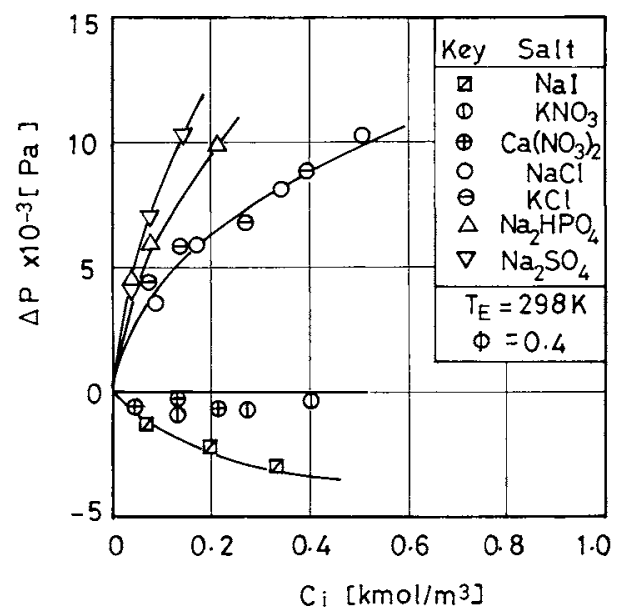

Fig. 8. Effect of salts on the difference of swelling pressure $\Delta P$ between that in distilled water and that in salt solution at $298 \mathrm{~K}$.

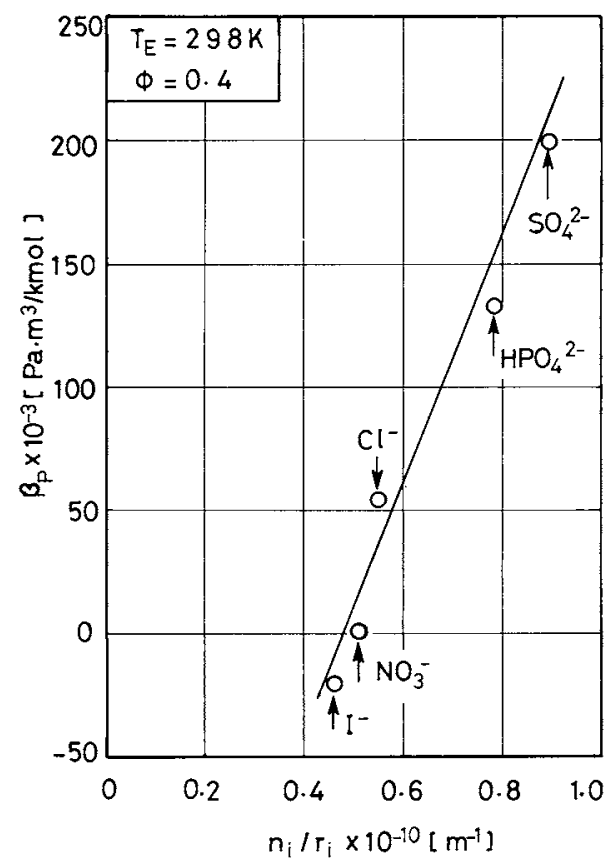

Fig. 9. Dependence of $\beta_{P}=\lim _{C_{i} \rightarrow 0}\left(A P / C_{i}\right)$ on the ratio $n_{i} / r_{i}$ of valency to radius of anion group

cerned with the valency and size of the anion group of the salt.

\section{Conclusion}

The swelling pressure observed in the swelling process of nonionic poly(vinylmethylether) gel (PVMEG) was examined and the results are summarized as follows:

1) Swelling pressure appearing in the swelling process of gel placed in the space between two plates increased with decrease of the space, i.e., with the gel's porosity, and with decrease in temperature.

2) Swelling pressure is primarily due to the contribution of hydrogen bonds in the polymer network 
with water molecules.

3) The effect of salt on swelling pressure is estimated by the ratio of valency to radius of the anion in the salt.

\begin{tabular}{|c|c|c|c|}
\hline \multicolumn{4}{|c|}{ Nomenclature } \\
\hline$C_{i}$ & $=$ & salt concentration & $\left.\mathrm{ol} \cdot \mathrm{m}^{-3}\right]$ \\
\hline$f$ & & $\begin{array}{l}\text { number of dissociated ions per effective } \\
\text { polymer chain }\end{array}$ & {$[-]$} \\
\hline$f_{H}$ & $=$ & experimental coefficient in Eq. (4) & {$[\mathrm{Pa}]$} \\
\hline$\Delta F$ & & $\begin{array}{l}\text { free energy change associated with contact } \\
\text { between polymer segments in shrunken sta } \\
\text { and solvent molecules }\end{array}$ & {$[\mathrm{J}]$} \\
\hline$H_{0}$ & $=$ & initial length of gel & {$[\mathrm{m}]$} \\
\hline$\Delta H$ & $=$ & distance between two plates in Fig. 1 & {$[\mathrm{~m}]$} \\
\hline$k$ & $=$ & Boltzman constant & {$\left[\mathrm{J} \cdot \mathrm{K}^{-1}\right]$} \\
\hline$N$ & $=$ & Avogadro's number & {$\left[\mathrm{mol}^{-1}\right]$} \\
\hline$n_{i}$ & $=$ & valency of ion & {$[-]$} \\
\hline$P$ & $=$ & equilibrium swelling pressure & {$[\mathrm{Pa}]$} \\
\hline$P_{E}$ & $=$ & swelling pressure due to rubber elasticity & {$[\mathrm{Pa}]$} \\
\hline$P_{H}$ & $=$ & $\begin{array}{l}\text { contribution of hydrogen bond to } \\
\text { swelling pressure }\end{array}$ & {$[\mathrm{Pa}]$} \\
\hline$P_{M}$ & & $\begin{array}{l}\text { swelling pressure due to mixing free } \\
\text { energy change }\end{array}$ & {$[\mathrm{Pa}]$} \\
\hline$p$ & $=$ & apparent equilibrium swelling force & {$[\mathrm{N}]$} \\
\hline$p_{t}$ & $=$ & apparent swelling force & {$[\mathrm{N}]$} \\
\hline$\Delta P$ & & $\begin{array}{l}\text { difference of swelling pressure between that } \\
\text { in distilled water and that in salt solution }\end{array}$ & {$[\mathrm{Pa}]$} \\
\hline$q$ & $=$ & experimental coefficient in Eq. (4) & {$[-]$} \\
\hline$r_{i}$ & $=$ & radius of ion & [m] \\
\hline$T$ & $=$ & temperature & {$[\mathrm{K}]$} \\
\hline$T_{E}$ & $=$ & temperature of water solution & {$[\mathrm{K}]$} \\
\hline$T_{G 0}$ & $=$ & initial temperature of gel & {$[\mathrm{K}]$} \\
\hline
\end{tabular}

$t \quad=$ time $[\mathrm{s}]$

$V \quad=$ volume of gel $\left[\mathrm{m}^{3}\right]$

$V_{0} \quad=$ initial volume of gel $\quad\left[\mathrm{m}^{3}\right]$

$v \quad=$ molar volume of solvent $\quad\left[\mathrm{m}^{3} \cdot \mathrm{mol}^{-1}\right]$

$\beta_{P} \quad=$ slope at infinite dilution in Fig. 8 $\left(=\lim \left(\Delta P / C_{i}\right) \quad\left[\mathrm{Pa} \cdot \mathrm{m}^{3} \cdot \mathrm{kmol}^{-1}\right]\right.$

$=$ experimental coefficient in Eq. (4) [-]

$=$ number of constituent chains per unit volume of gel at $\psi=\psi_{0}$

$=$ porosity of gel $\left(=\left(V-V_{0}\right) / V\right)$

$=$ volume fraction of cross-linked network $\quad[-]$

$=$ volume fraction of uncross-linked single polymer chain

\section{Literature Cited}

1) Flory, P. J.: "Principles of Polymer Chemistry," p. 576, Cornell University Press, Ithaca (1953).

2) Hirasa, O.: Polymer Preprints, 36, 2951 (1987).

3) Huang, X., H. Unno, T. Akehata and O. Hirasa: J. Chem. Eng. Japan, 20, 123 (1987).

4) Huang, X., H. Unno, T. Akehata and O. Hirasa: Kagaku Kogaku Ronbunshu, 13, 518 (1987).

5) Huang, X., H. Unno, T. Akehata and O. Hirasa: J. Chem. Eng. Japan, 21, 10 (1988).

6) Huang, X., H. Unno, T. Akehata and O. Hirasa: Preprints of the Hokkaido Meeting of The Soc. of Chem. Engrs., Japan, p. 205 (1987).

7) Nakano, Y., M. Kouchi, H. Nagasawa and M. Imai: Polymer Preprints, 36, 2939 (1987).

8) Tanaka, T., P. Fillmore, S. T. Sun and I. Nishino: Physical Review Letters, 45, 1636 (1980).

\title{
EFFECT OF INTERNAL BAFFLES ON CONVERSION OF HYDROGEN CHLORIDE OXIDATION AND PRESSURE FLUCTUATIONS IN A FLUIDIZED CATALYST BED
}

\author{
TAKAMI KAI AND TAKESHIGE TAKAHASHI \\ Department of Chemical Engineering, Kagoshima University, Kagoshima 890 \\ MASANOBU AJIOKA, SHINJI TAKENAKA AND NAOBI TOKUNAGA \\ Mitsui Toatsu Chemicals, Inc., Tokyo 100
}

Key Words: Fluidization, Fluidized Catalyst Bed, Internal Baffles, Hydrogen Chloride Oxidation, Pressure Fluctuations

Oxidation of gaseous hydrogen chloride into chlorine is known as the Deacon reaction. ${ }^{1.3)}$ By modifying the component of the catalyst, a new fluidized catalyst bed process (MT-Chlor) has been developed

Received February 25, 1988 . Correspondence concerning this article should be addressed to T. Kai. to produce chlorine. ${ }^{6)}$ In a bench-scale reactor for the MT-Chlor process, the effect of internal baffles on $\mathrm{HCl}$ conversion was studied. In addition, pressure fluctuations were measured in a cold model. The results of these experiments were related to each other and examined on the basis of the effect of internal 